\title{
Budesonide/formoterol and formoterol provide similar rapid relief in patients with acute asthma showing refractoriness to salbutamol ED Bateman*1, L Fairall ${ }^{1}$, DM Lombardi ${ }^{2}$ and R English ${ }^{1}$
}

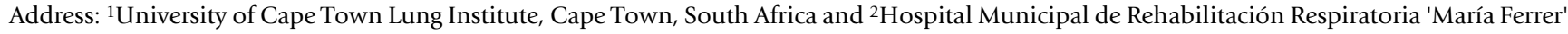 \\ Buenos Aires, Argentina \\ Email: ED Bateman* - ebateman@uctgsh1.uct.ac.za; L Fairall - Ifairall@uctgsh1.uct.ac.za; DM Lombardi - ebateman@uctgsh1.uct.ac.za; \\ R English - renglish@uctgsh1.uct.ac.za \\ * Corresponding author
}

Published: 24 January 2006

Respiratory Research 2006, 7:13 doi:10.1186/1465-9921-7-13

This article is available from: http://respiratory-research.com/content/7///13

(C) 2006 Bateman et al; licensee BioMed Central Ltd.

This is an Open Access article distributed under the terms of the Creative Commons Attribution License (http://creativecommons.org/licenses/by/2.0), which permits unrestricted use, distribution, and reproduction in any medium, provided the original work is properly cited.
Received: 01 September 2005

Accepted: 24 January 2006

\begin{abstract}
Background: To compare the efficacy and safety of budesonide/formoterol (Symbicort ${ }^{\circledR}$ ) with formoterol $\left(\mathrm{Oxis}^{\circledR}\right)$ in the treatment of patients with acute asthma who showed evidence of refractoriness to short-acting $\beta_{2}$-agonist therapy.

Methods: In a 3 hour, randomized, double-blind study, a total of II 5 patients with acute asthma (mean $\mathrm{FEV}, 40 \%$ of predicted normal) and a refractory response to salbutamol (mean reversibility $2 \%$ of predicted normal after inhalation of $400 \mu \mathrm{g}$ ), were randomized to receive either budesonide/ formoterol $(320 / 9 \mu \mathrm{g}, 2$ inhalations at $\mathrm{t}=-5$ minutes and 2 inhalations at 0 minutes [total dose 1280/36 $\mu \mathrm{g}$ ]) or formoterol $(9 \mu \mathrm{g}, 2$ inhalations at $\mathrm{t}=-5$ minutes and 2 inhalations at 0 minutes [total dose $36 \mu \mathrm{g}$ ]). The primary efficacy variable was the average $\mathrm{FEV}$, from the first intake of study medication to the measurement at 90 minutes. Secondary endpoints included changes in FEV at other timepoints and change in respiratory rate at 180 minutes. Treatment success, treatment failure and patient assessment of the effectiveness of the study medication were also measured.

Results: FEV increased after administration of the study medication in both treatment groups. No statistically significant difference between the treatment groups was apparent for the primary outcome variable, or for any of the other efficacy endpoints. There were no statistically significant between-group differences for treatment success, treatment failure or patient assessment of medication effectiveness. Both treatments were well tolerated.

Conclusion: Budesonide/formoterol and formoterol provided similarly rapid relief of acute bronchoconstriction in patients with asthma who showed evidence of refractoriness to a shortacting $\beta_{2}$-agonist.
\end{abstract}

\section{Introduction}

Patients presenting with symptoms of acute asthma are traditionally treated with short-acting $\beta_{2}$-agonists $[1,2]$. Formoterol is a long-acting $\beta_{2}$-agonist with a rapid onset of action, producing bronchodilation within 1-3 minutes of inhalation [3-5]. This effect is comparable with that of salbutamol [5], making formoterol suitable for the treatment of acute asthma. In this setting, formoterol has proved both safe and efficacious [6,7]. A large study performed in an emergency room setting by Boonsawat and colleagues [6] showed that high-dose formoterol was as rapid and effective as high-dose salbutamol in reversing 


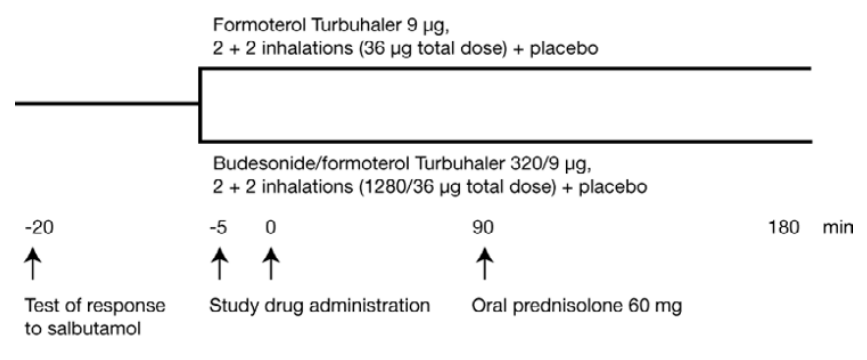

Figure I

Study design.

bronchoconstriction in patients with severe asthma, but formoterol produced greater improvements than salbutamol in lung function over 4 hours. For this reason, formoterol has been licensed for use as both maintenance therapy and as an alternative to salbutamol and terbutaline for the relief of acute asthma symptoms.

Asthma patients experiencing acute symptoms may use their $\beta_{2}$-agonist reliever medication repeatedly. This can result in downregulation of $\beta_{2}$-receptors and consequent relative refractoriness to the bronchodilatory effects of this class of drug $[8,9]$. High doses of inhaled corticosteroid (ICS) have been reported to upregulate these receptors and restore $\beta_{2}$-agonist responsiveness [10].
In order to study the potential of this favourable interaction, Pansegrouw [11] examined the use of combined ICS and short-acting $\beta_{2}$-agonist treatment in patients with acute asthma who initially showed no response to $\beta_{2}$-agonist therapy. It was reported that 'priming' patients with ICS before commencing nebulised $\beta_{2}$-agonist treatment was more effective than therapy with the $\beta_{2}$-agonist alone at improving features of the exacerbation, including lung function [11]. Although, to our knowledge, this study has not been repeated, it raises the prospect that budesonide and formoterol - which are now available together in a combination inhaler (Symbicort ${ }^{\oplus}$; budesonide/formoterol) - may be more effective than formoterol given alone in treating patients with acute asthma who initially show no response to $\beta_{2}$-agonist therapy. The present study was designed to compare the efficacy of budesonide/formoterol with that of formoterol for the treatment of patients with acute asthma who had evidence of relative refractoriness to the administration of a short-acting $\beta_{2}$-agonist.

\section{Patients and methods \\ Patients}

Patients aged $\geq 12$ years presenting with acute asthma were recruited from a total of 8 centres in Argentina, Mexico and South Africa. All patients were required to have asthma, as defined by the American Thoracic Society criteria (including symptoms of wheeze, episodic cough, and dyspnea) [12], with a pre-bronchodilator forced expiratory volume in 1 second $\left(\mathrm{FEV}_{1}\right.$; measured on arrival in the

Table I: Baseline demographics and clinical characteristics

\begin{tabular}{|c|c|c|}
\hline Characteristic & Formoterol $(n=57)$ & Budesonide/formoterol $(n=58)$ \\
\hline Male/female, $\mathrm{n}$ & $20 / 37$ & $22 / 36$ \\
\hline Age, years (range) & $43.9(12-72)$ & $45.9(13-78)$ \\
\hline \multicolumn{3}{|l|}{ Race, n (\%) } \\
\hline Caucasian & $39(68)$ & $37(64)$ \\
\hline Black & 0 & I (2) \\
\hline Other & $18(32)$ & $20(34)$ \\
\hline Asthma duration, years (range) & $20(1-65)$ & $22.5(0-54)$ \\
\hline \multicolumn{3}{|l|}{ Acute severe asthma exacerbations in the 12 months before study entry } \\
\hline Number (\%) of patients with event & $56(98)$ & $54(93)$ \\
\hline Mean number of events (range) & $6.3(1-30)$ & $6.4(1-40)$ \\
\hline \multicolumn{3}{|l|}{ Duration of current asthma exacerbation, $n$} \\
\hline$<6$ hours & 2 & 2 \\
\hline $6-12$ hours & 4 & I \\
\hline $12-24$ hours & 4 & 11 \\
\hline$>24$ hours & 47 & 43 \\
\hline $\mathrm{FEV}_{1}, \mathrm{~L}$ (range) & $1.15(0.7-2.0)$ & $1.12(0.6-1.9)$ \\
\hline $\mathrm{FEV}_{1}, \%$ of predicted normal (range) & $41(30-55)$ & $40(26-55)$ \\
\hline Reversibility, \% of predicted normal (range) & $2.4(-8$ to +8$)$ & $2.1(-7$ to +8$)$ \\
\hline Reversibility, \% of baseline (range) & $5.8(-18$ to +23$)$ & $5.5(-16$ to +20$)$ \\
\hline Number (\%) of patients prescribed long-acting $\beta_{2}$-agonist at entry & $4(7)$ & $6(10)$ \\
\hline Number (\%) of patients prescribed ICS at entry ${ }^{\mathrm{a}}$ & $16(28)$ & $17(29)$ \\
\hline ICS at entry, $\mu g$ (range) & $768(160-2560)$ & $624(100-2400)$ \\
\hline
\end{tabular}

All values are presented as absolute numbers or as means, except asthma duration, for which the median is given. aDose of inhaled corticosteroid (budesonide equivalents) in patients receiving inhaled corticosteroid. $\mathrm{FEV}_{1}=$ forced expiratory volume in I second; ICS = inhaled corticosteroids. 


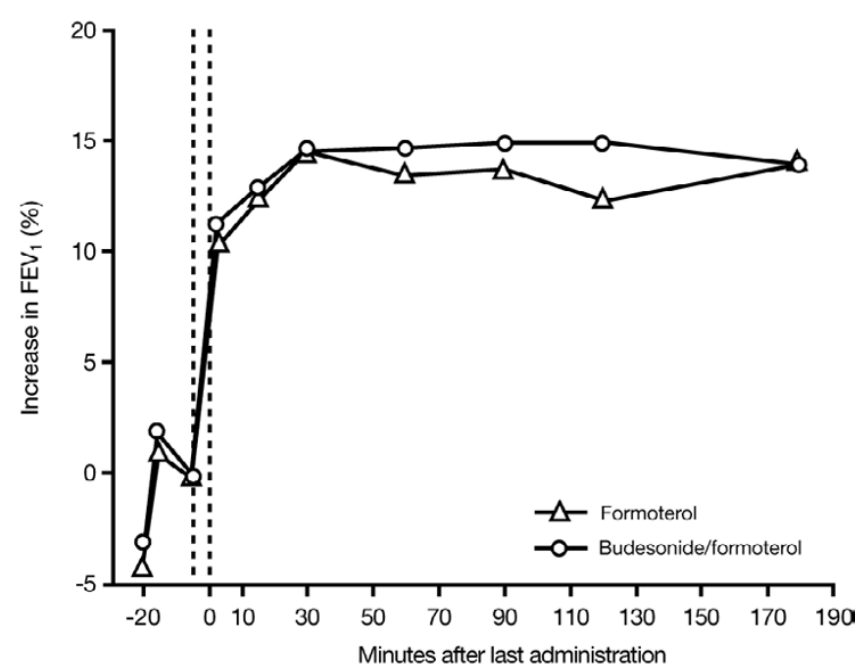

Figure 2

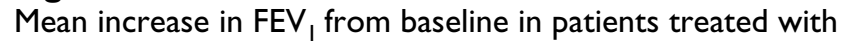
either formoterol or budesonide/formoterol. At screening ( $t$ $=-20$ minutes), salbutamol $400 \mu \mathrm{g}$ was administered to all patients to establish their relative refractoriness to $\beta_{2}$-agonist therapy. Patients in the formoterol group received formoterol $9 \mu \mathrm{g}, 2$ inhalations at $\mathrm{t}=-5$ minutes and 2 inhalations at 0 minutes (total dose $36 \mu \mathrm{g}$ ). Patients treated with budesonide/formoterol received budesonide/formoterol $320 / 9 \mu \mathrm{g}$, 2 inhalations at $\mathrm{t}=-5$ minutes and 2 inhalations at 0 minutes (total dose $1280 / 36 \mu \mathrm{g}$ ). The timing of study drug administration is shown by vertical dotted lines on the figure. Patients received oral prednisolone $60 \mathrm{mg} 90$ minutes after the last administration of study drug.

acute setting) $\geq 30 \%$ and $\leq 55 \%$ of predicted normal. In addition, patients had to have a relative lack of reversibility, as demonstrated by their $\mathrm{FEV}_{1}$ improving by $8 \%$ or less of predicted normal, 10 minutes after receiving salbutamol $400 \mu \mathrm{g}$ from a pressurised metered-dose inhaler.

Exclusion criteria included: acute severe asthma (defined as an inability to generate an $\mathrm{FEV}_{1}$ value, an $\mathrm{FEV}_{1}$ of less than $30 \%$ predicted, or asthma requiring transfer to an intensive care unit on initial assessment); use of ICS within the 8 hours preceding the baseline measurements; receipt of oral or other systemic steroids in the 48 hours before the baseline measurements; $\beta$-blocker therapy (including eye drops); any significant disease or concomitant disorder; and known sensitivity to the study medication or lactose. Patients $\geq 45$ years of age with a history of $\geq 10$ pack-years of smoking were also excluded from the study.

During the treatment period, patients were not permitted to receive any asthma medication other than the investigational product, although oxygen therapy was allowed. Other medication considered necessary for the patient's safety and well-being, and early withdrawal from the study, were permitted at the discretion of the investigator.

\section{Study design}

This was a 180 minute, double-blind, double-dummy, randomized, parallel-group multicentre study (Study 0693). The study was performed in accordance with the ethical principles in the Declaration of Helsinki, Good Clinical Practice guidelines, in addition to applicable local regulatory requirements, and the protocol was approved by local ethics review boards. Before any procedure relating to the study was performed, written informed consent was obtained from the patients and, where applicable, from the patient's parent or legal guardian.

The study design is shown in Figure 1. After the test of response to salbutamol (Ventolin ${ }^{\oplus}$, Glaxo Wellcome, UK; 100 or $200 \mu \mathrm{g}$ [total dose $400 \mu \mathrm{g}$ ], administered using a pressurised metered-dose inhaler with a Volumatic spacer [Allen \& Hanburys, UK]), eligible patients received either budesonide/formoterol (Symbicort ${ }^{\circledR}$ Turbuhaler $^{\circledast}$, AstraZeneca, Sweden; 320/9 $\mu \mathrm{g}$, 2 inhalations at $\mathrm{t}=-5$ minutes and a further 2 inhalations at $\mathrm{t}=0$ minutes [total dose $1280 / 36 \mu \mathrm{g}$ ], plus 2 inhalations of formoterol placebo containing lactose at $\mathrm{t}=-5$ minutes and at $\mathrm{t}=0$ minutes) or formoterol (Oxis ${ }^{\circledast}$ Turbuhaler ${ }^{\circledast}$, AstraZeneca, Sweden; 9 $\mathrm{ug}$, 2 inhalations at $\mathrm{t}=-5$ minutes and a further 2 inhalations at $\mathrm{t}=0$ minutes [total dose $36 \mu \mathrm{g}$ ], plus 2 inhalations of budesonide/formoterol placebo containing lactose at $\mathrm{t}$ $=-5$ minutes and at $\mathrm{t}=0$ minutes). Oral prednisolone (Approved Prescription Services, UK; $5 \mathrm{mg}$ per tablet, 12 tablets [total dose $60 \mathrm{mg}$ ]) was administered to all patients 90 minutes after they received the second dose of study medication.

\section{Efficacy assessments}

The primary efficacy variable was the average $\mathrm{FEV}_{1}$ from the first intake of study drug to the measurement at 90 minutes. The following were assessed as secondary efficacy variables: the change in $\mathrm{FEV}_{1}$ at $\mathrm{t}=3,15,60,90$ and 180 minutes after the last intake of study medication; the change in respiratory rate at 180 minutes; the proportion of patients with treatment success at 90 and 180 minutes; the proportion of patients with treatment failure at 180 minutes; and the effectiveness of the study medication at 3 and 15 minutes.

$\mathrm{FEV}_{1}$ was measured by spirometry according to European Respiratory Society (ERS) recommendations [13]. Respiratory rate was counted for 1 minute at baseline $(\mathrm{t}=-15$ minutes) and at 15, 30, 60, 90, 120, and 180 minutes after the last intake of study medication. Treatment success was judged by the investigator and defined in terms of a patient being fit for immediate discharge at 90 and 180 
minutes. If treatment was considered successful at 90 minutes, the patient still remained in the study for the 180minute period. Treatment failure was defined as a requirement for additional asthma treatment and/or hospitalization because of asthma during the timeframe of the study. A subjective assessment of the effectiveness of the study medication was determined by asking the patients whether or not they considered the medication to be effective. An uncertain response was recorded as 'no'.

\section{Safety assessments}

The incidence, severity and type of adverse events occurring during the study were recorded. Deterioration of asthma was not recorded as an adverse event unless it caused the patient to withdraw from the study or was classed as serious by the investigator. A serious adverse event was defined as an event that: caused death or was immediately life-threatening; required inpatient care or prolongation of hospitalization; resulted in persistent or significant disability or incapacity; or required medical intervention to prevent one of these outcomes.

Measurements of serum potassium, pulse rate, blood pressure, electrocardiogram (ECG) variables, and oxygen saturation were also used to assess safety. The outcome variables for serum potassium were the minimum and average values after administration. Blood samples for the determination of this variable were obtained at baseline $(\mathrm{t}$ $=-15$ minutes) and 30, 90 and 180 minutes after administration of the last dose of study medication.

\section{Statistical methods}

A sample size of 50 patients per group was required to have an $80 \%$ chance of detecting a difference of $12 \%$ between treatments in average $\mathrm{FEV}_{1}$ from the first intake of study drug to the 90 minute measurement (5\% significance level, $t$-test, two-sided alternative hypothesis).

Efficacy analyses were performed on the full analysis set; all patients who received at least one dose of study medication were included in the safety analysis. Changes in $\mathrm{FEV}_{1}$ were analysed using multiplicative analysis of variance (ANOVA), with treatment and country as fixed factors and the pre-administration value ( $\mathrm{t}=-5$ minutes $)$ as a covariate. The change in respiratory rate was analysed using additive ANOVA. The proportions of patients with treatment success, treatment failure and reports of effective medication were analysed using logistic regression models with treatment and country as factors. Odds ratios were estimated and described with 95\% confidence limits. Clinical laboratory data, vital signs and physical measurements relating to safety were compared between treatment groups with an additive ANOVA model. Adverseevent data were evaluated using primarily descriptive statistics.

\section{Results \\ Patients}

Patients were enrolled and treated between April 2002 and August 2003. A total of 277 patients were recruited into the study, 115 of whom fulfilled the inclusion criteria and were randomized to receive treatment with either budesonide/formoterol $(n=58)$ or formoterol $(n=57)$. One patient, who was randomized into the formoterol group, discontinued the study as a result of an adverse event. The full analysis set comprised all randomized patients.

The two treatment groups were comparable at baseline, in terms of both demographics and other clinical character-

Table 2: Treatment comparisons (budesonide/formoterol vs formoterol) for all FEV , outcome variables

\begin{tabular}{|c|c|c|c|c|}
\hline \multirow[b]{2}{*}{ Variable } & \multicolumn{2}{|c|}{ Mean $\%$ change from baseline ${ }^{a}$} & \multirow[b]{2}{*}{$\begin{array}{l}\text { Budesonide/formoterol vs formoterol: mean ratio, \% (95\% } \\
\text { confidence limits) }\end{array}$} & \multirow[b]{2}{*}{ p value } \\
\hline & $\begin{array}{l}\text { Formoterol } \\
\quad(n=57)\end{array}$ & $\begin{array}{l}\text { Budesonide/formoterol } \\
\qquad(\mathrm{n}=\mathbf{5 8})\end{array}$ & & \\
\hline$E_{a v}$ & 16.5 & 17.4 & $100.8(96.1,105.7)$ & 0.74 \\
\hline$E_{\max }$ & 26.3 & 27.2 & $100.7(95.1,106.7)$ & 0.80 \\
\hline $\mathrm{E}_{3}$ & 13.3 & 14.1 & $100.7(96.5,105.1)$ & 0.75 \\
\hline $\mathrm{E}_{15}$ & 15.8 & 16.4 & $100.5(95.9,105.3)$ & 0.82 \\
\hline$E_{60}$ & 17.2 & 18.6 & $101.2(95.8,106.9)$ & 0.67 \\
\hline$E_{90}$ & 18.2 & 19.7 & $101.3(95.5,107.3)$ & 0.67 \\
\hline $\mathrm{E}_{180}$ & 16.5 & 16.5 & $100.0(93.7,106.7)$ & 1.0 \\
\hline
\end{tabular}

aBased on adjusted ratios from an analysis of variance model.

$E_{a v}$ is the average $\mathrm{FEV}_{1}$ (area under the curve) from the first intake of study drug (-5 minutes) to the +90 -minute measurement (primary outcome variable). $E_{\max }$ is the change in $F E V_{1}$ from pre-administration to the maximal value after administration. $E_{3}, E_{15}, E_{60}, E_{90}$ and $E_{180}$ are the changes in $\mathrm{FEV}$, from pre-administration to $3,15,60,90$ and 180 minutes after the last administration of the study drug, respectively.

$\mathrm{FEV}_{1}=$ forced expiratory volume in I second. 
istics (Table 1). Patients reported a background of chronic severe asthma of longstanding duration (median 21 years). In the year before entry into the trial, $96 \%$ of the patients had experienced an exacerbation, with a mean number of 6 events per patient per year. Despite this, only $29 \%$ of the patients reported using preventative ICS. At study entry, the mean $\mathrm{FEV}_{1}$ was $1.13 \mathrm{~L}$ (40\% of the predicted normal value). After treatment with salbutamol $400 \mu \mathrm{g}$, the mean reversibility in $\mathrm{FEV}_{1}$ was $5.6 \%$ of the baseline value ( $2.2 \%$ of predicted normal).

\section{Efficacy}

\section{Lung function}

$\mathrm{FEV}_{1}$ increased after study drug administration in both treatment groups (Figure 2). The average increase from baseline in $\mathrm{FEV}_{1}$ (area under the curve) from the first intake of study drug to the 90-minute measurement was $17.4 \%$ in patients receiving budesonide/formoterol and $16.5 \%$ in formoterol-treated patients. There was no significant difference between the groups for the primary outcome variable.

There were no statistically significant differences between the budesonide/formoterol and formoterol treatment groups with regard to either the change in $\mathrm{FEV}_{1}$ at any of the timepoints analysed over the full 180-minute assessment period, or for the maximal $\mathrm{FEV}_{1}$ value achieved (Table 2).

\section{Respiratory rate}

The respiratory rate decreased over time in both treatment groups (Figure 3), with no statistically significant between-group difference being apparent. In patients receiving budesonide/formoterol, the mean pre-dose value (breaths per minute) was 23.5, decreasing to 19.2 at $\mathrm{t}=180$ minutes. The corresponding values for the formoterol group were 22.6 and 18.4, respectively.

Treatment success, treatment failure and effectiveness of medication There was a slight numerical advantage in the percentage of patients reporting treatment success in the budesonide/ formoterol group (79\% and $90 \%$ at 90 and 180 minutes, respectively) compared with those being treated with formoterol (74\% and $84 \%$ at 90 and 180 minutes, respectively). Despite the initially poor response to salbutamol in all patients, only a small minority of treatment failures were seen in both groups $(10 \%$ and $16 \%$ for patients treated with budesonide/formoterol and formoterol, respectively). The majority of patients described their medication as effective. After 3 minutes, $97 \%$ of patients receiving budesonide/formoterol considered their medication to be effective; this figure remained at $97 \%$ at 15 minutes. The corresponding values for the formoterol treatment group were $93 \%$ and $96 \%$, respectively.
There were no statistically significant between-group differences for any of these variables.

\section{Safety}

Adverse events

Nine patients in each treatment group (16\%) reported a total of 24 adverse events. There were 13 adverse events in patients receiving budesonide/formoterol and 11 in the formoterol treatment group. These events were mostly mild or moderate in intensity. Tremor and headache were the most frequently reported adverse events and there were no differences between the treatment groups in the incidence of patients reporting these symptoms (Table 3).

One patient in the formoterol group discontinued the study after 2 hours because of worsening asthma. A patient in the budesonide/formoterol group suffered a serious deterioration in asthma symptoms but managed to complete the study. These two episodes were reported as serious adverse events (asthma aggravated). Neither was considered to be causally related to the study drug. There were no deaths during the study.

\section{Clinical laboratory data and other safety evaluations}

Treatment with both budesonide/formoterol and formoterol was well tolerated and systemic effects were similar for both treatments. The majority of patients in both treatment groups had normal serum potassium before treatment and at the end of the study period. The mean values for the average serum potassium during the 180 minutes after study drug administration were 3.82 and 3.88 $\mathrm{mmol} / \mathrm{L}$ for the budesonide/formoterol and formoterol groups, respectively. The corresponding mean pre-dose values were 3.83 and $4.01 \mathrm{mmol} / \mathrm{L}$, respectively. Abnormally low values $(<3.0 \mathrm{mmol} / \mathrm{L})$ were reported for two patients 180 minutes after the last intake of study medication; both of these patients were in the formoterol group. The lowest treatment value recorded for a patient in the budesonide/formoterol group was a transient decrease to $2.7 \mathrm{mmol} / \mathrm{L}$ after 90 minutes; the lowest value for formoterol-treated patients was $2.6 \mathrm{mmol} / \mathrm{L}$, which occurred in a patient with a pre-dose value of $2.4 \mathrm{mmol} / \mathrm{L}$. In the formoterol group, one case of hypokalaemia was reported as an adverse event. Overall, the effects of budesonide/formoterol and formoterol on serum potassium were small and were not considered to be clinically important; there were no statistically significant differences between the treatment groups with regard to this parameter.

Vital signs, ECG parameters and oxygen saturation also showed only small changes over time during the course of the study. There were no statistically significant differences between the treatments for the average or maximum/minimum values for any of these variables, with the exception of heart rate, for which budesonide/formoterol 
had a lower maximum value (mean of 91.6 beats per minute) than formoterol (mean of 94.3 beats per minute; $\mathrm{p}=0.026)$.

\section{Discussion}

Patients with acute asthma require efficacious medication to reduce bronchoconstriction. In this study, budesonide/ formoterol and formoterol proved similarly safe and effective for the treatment of patients with acute asthma who had not initially responded adequately to the shortacting $\beta_{2}$-agonist, salbutamol. There was no difference between the two treatments with regard to their efficacy and tolerability over the 180-minute assessment period. At the end of the study, a high proportion of patients in both groups had been successfully treated.

Previous studies have demonstrated that formoterol is at least as effective as salbutamol for the treatment of acute exacerbations [7,6] and its role in providing as-needed relief from symptoms has been well demonstrated $[14,15]$. The similar efficacy of budesonide/formoterol and formoterol seen in our patient population suggests that budesonide/formoterol can also be used for as-

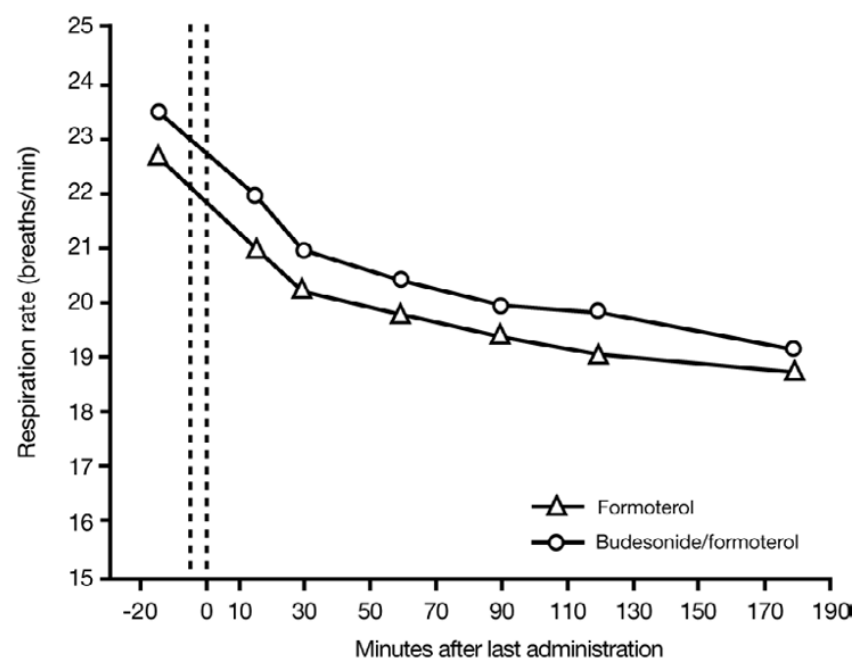

\section{Figure 3}

Change in respiratory rate in patients treated with formoterol or budesonide/formoterol. At screening ( $t=-20 \mathrm{~min}$ utes), salbutamol $400 \mu \mathrm{g}$ was administered to all patients to establish their relative refractoriness to $\beta_{2}$-agonist therapy. Patients in the formoterol group received formoterol $9 \mu \mathrm{g}, 2$ inhalations at $\mathrm{t}=-5$ minutes and 2 inhalations at 0 minutes (total dose $36 \mu \mathrm{g}$ ). Patients treated with budesonide/formoterol received budesonide/formoterol 320/9 $\mu$ g, 2 inhalations at $\mathrm{t}=-5$ minutes and 2 inhalations at 0 minutes (total dose $1280 / 36 \mu \mathrm{g})$. The timing of study drug administration is shown by vertical dotted lines on the figure. Patients received oral prednisolone $60 \mathrm{mg} 90$ minutes after the last administration of study drug. needed symptom relief in patients with acute severe bronchospasm. Further evidence to support this has been obtained by Balanag and colleagues [16] who demonstrated that budesonide/formoterol and salbutamol had similar short-term efficacy in relieving acute asthma exacerbations. However, unlike the Balanag study, we enrolled patients with acute asthma who demonstrated initial refractoriness to salbutamol. We were, however, unable to demonstrate evidence of an enhanced $\beta_{2}$-receptor response in patients receiving therapy with ICS, as has been described previously $[10,11,17]$. A possible reason for our results is that, despite our patients' poor response to salbutamol $400 \mu \mathrm{g}$ (mean improvement in $\mathrm{FEV}_{1}$ of only $5.6 \%$ from baseline), they may not have been sufficiently refractory to demonstrate the potential benefit provided by ICS. This is suggested by the rather good initial responses (additional improvements in $\mathrm{FEV}_{1}$ of $13.3 \%$ and $18.2 \%$ at 3 minutes and 90 minutes after dosing, respectively) in the patients who received formoterol alone.

The identification of patients with refractoriness to $\beta_{2}$ agonists in acute asthma is complicated by both conceptual and methodological problems. Among the former are the difficulty in distinguishing between $\beta_{2}$-agonist refractoriness caused by downregulation - a feature that has been confirmed in vitro [8], but not in vivo - and a lack of clinical response caused by pathological changes in asthmatic airways (e.g. mucus plugging, oedema of the bronchial wall) and chronic structural changes (such as airway remodelling) $[18,19]$. Assays of $\beta_{2}$-agonist receptor density on circulating monocytes, together with other in vitro tests, may have been useful, but the results of such testing would not have been available in time to assist with patient selection for this acute study. A minority of patients were being treated with ICS at the time of their exacerbation, but most had a history of previous exacerbations, suggesting that many patients' asthma had been chronically undertreated. In addition, for $78 \%$ of the patients the acute symptoms had lasted for $>24 \mathrm{~h}$ before study entry and so it is possible that, in many patients, airway pathology may have been well established. Consequently, airway pathology, rather than downregulation of $\beta_{2}$-agonist receptors, may have accounted for $\beta_{2}$-agonist refractoriness.

Another challenge when selecting patients for a study such as the one we have reported here, is to establish accurately patients' prior dosing with $\beta_{2}$-agonists. Patient recall of $\beta_{2}$ agonist use is often poor. Moreover, we waited only 15 minutes after administering salbutamol $400 \mu \mathrm{g}$ before patients were treated with the study drug. This was necessary because patients were distressed and it was considered neither safe nor compassionate to await the peak effect of the salbutamol (between 15 and 30 minutes after 
Table 3: Most commonly reported adverse events in patients treated with formoterol or budesonide/formoterol

\begin{tabular}{|c|c|c|}
\hline Preferred term & Formoterol $(n=57)$ & Budesonide/formoterol $(n=58)$ \\
\hline Tremor & $4(7)$ & $4(7)$ \\
\hline Headache & $3(5)$ & $3(5)$ \\
\hline Asthma aggravated & I (2) & I (2) \\
\hline Tachycardia & $2(4)$ & 0 \\
\hline $\mathrm{AE}$ associated with test procedure & 0 & I (2) \\
\hline T-wave changes & 0 & I (2) \\
\hline Chest pain & 0 & $1(2)$ \\
\hline Hypokalaemia & $I(2)$ & 0 \\
\hline Dizziness & 0 & I (2) \\
\hline Pruritus & 0 & I (2) \\
\hline
\end{tabular}

The number (\%) of patients with each adverse event is given.

$\mathrm{AE}=$ adverse event.

administration) to exclude patients who responded more slowly. In contrast, patients were followed for longer periods after receiving the study drugs. There was, however, some evidence that the initial response to salbutamol was already at a plateau or in decline when the study drugs were administered, although there was no evidence of a loss of effect with either of the study drugs during the 3hour assessment (Figure 2).

Differences in methods of patient selection may have accounted for the differences between our results and those reported with early ICS dosing in previous trials $[10,11,17]$. However, it should be noted that Pansegrouw [11] provided little detail from which to gauge his patients' prior treatment or degree of refractoriness to $\beta_{2^{-}}$ agonists, although the patients in that study had asthma of a similar severity to the patients enrolled into our study.

There are other possible reasons for a lack of additional benefit with ICS. For instance, if patients had received previous treatment with corticosteroids, there might have been a carry-over of the effect of this medication. Although patients were not permitted to receive ICS within the 8 hours before the baseline measurements, or oral/systemic steroids in the 48 hours before the baseline measurements, a protective effect of prior dosing may still have been apparent. However, as only $29 \%$ of the patients were using ICS on study entry, this may not account for the lack of additional benefit seen with budesonide/formoterol compared with formoterol in this study. The early response to ICS may depend on the repeated administration of high doses of the drug, as postulated by Rodrigo and Rodrigo [17]. In their study, patients with acute asthma of more than 24 hours' duration had a significantly better response when treated with high cumulative doses of flunisolide in addition to salbutamol than those treated with salbutamol alone. Patients in our study received only two doses of budesonide/formoterol, which may not have been sufficient for a meaningful topical response. Finally, there are limitations to using spirometry alone in determining nonresponsiveness to $\beta$-agonists.

Pansegrouw [11] is not alone in demonstrating the effect of ICS in refractory asthma. Aziz and Lipworth [10] reported that a bolus of inhaled budesonide $(1600 \mu \mathrm{g})$ rapidly reversed formoterol subsensitivity to adenosine monophosphate bronchoprotection in patients with asthma who were receiving regular formoterol. Additionally, other mechanisms of action of ICS in acute asthma have been proposed. Engel and colleagues [20] demonstrated improvements in lung function over 3 hours with budesonide administered alone (i.e. in the absence of $\beta_{2^{-}}$ agonists) versus placebo. While an improvement in lung function was evident 1 hour after drug administration, the effects increased over time to become statistically significantly different compared with placebo at 3-4 hours [20]. In the present study, efficacy data were collected over a 180-minute time period. Measurements extending beyond this timeframe may have proved valuable in assessing the contribution of budesonide to improving lung function. However, for ethical reasons all patients were treated with oral prednisolone 90 minutes after receiving the last dose of study medication, and this may have limited the utility of observations continuing for longer than 3 hours.

It is also possible that the dose of budesonide used in this study was too low. In patients who deteriorate whilst on regular doses of ICS, doubling the maintenance dose when symptoms of an exacerbation become apparent has not been shown to be effective in preventing the exacerbation $[21,22]$, but a fourfold increase in dose at the onset of an exacerbation may be beneficial [23]. These studies [21-23] examined the effects of treatment on patients over weeks and months; the study that we describe here assessed the efficacy of treating exacerbations over a 180minute time period. Studies involving budesonide/formoterol for maintenance and reliever therapy have shown 
that timely increases in the budesonide/formoterol dose as the symptoms of loss of control of asthma become apparent can result in a marked reduction in exacerbations $[24,25]$. These results suggest that treatment with an ICS and long-acting $\beta_{2}$-agonist combination (at the dose administered in the present study) is effective in preventing severe exacerbations if given very early, when the symptoms of loss of asthma control first become apparent, but may be less beneficial for patients in whom an exacerbation has become established. In our study investigating symptom relief in patients with acute asthma, the long-acting $\beta_{2}$-agonist alone was as effective as the combination therapy - even in patients presenting for emergency treatment who had used their short-acting $\beta_{2^{-}}$ agonist liberally and appeared to be refractory to $\beta_{2}$-agonist therapy, as judged by poor bronchodilatory response to short-acting $\beta_{2}$-agonists.

In addition to being effective, both budesonide/formoterol and formoterol were safe and well tolerated in the present study. The patterns of adverse events raised no safety concerns and, overall, the changes over time in systemic effects were very minor. These results are in line with those from earlier studies. Ankerst and colleagues [26] have reported systemic effects associated with the administration of budesonide/formoterol to be small, and the systemic effects of formoterol have generally been reported as minor and similar to salbutamol $[6,7,16,27]$.

In conclusion, budesonide/formoterol and formoterol provide rapid relief of acute bronchoconstriction in patients with asthma, producing effects of a similar magnitude. Both preparations are well tolerated.

\section{Acknowledgements}

The authors would like to acknowledge the assistance of Nicole Hemsley, Tracey van Rensburg, Nombubalo Tsutsu and the emergency room staff at the Retreat and Lotus River Community Health Centres in Cape Town who provided help with the clinical conduct of the study. AstraZeneca, Lund, Sweden, supported this study. Per ER Larsson gave assistance with statistical analysis and interpretation. We thank Andrew Lockley, from Adelphi Communications Ltd, who provided medical writing support on behalf of AstraZeneca.

\section{References}

I. British Thoracic Society (BTS): British guidelines on the management of asthma. Thorax 2003, 58(Suppl I): I-94.

2. Global Initiative for Asthma (GINA): Global Strategy for Asthma Management and Prevention (updated 2004). National Institutes of Health [NIH] publication No. 02-3659 2004 [http://www.ginas thma.org/Guidelineitem.asp?! | =2\&12=| \&int|d=987\&archived=I].

Bethesda, MD: MIH Accessed on 9 February 2005

3. Palmqvist M, Persson G, Lazer L, Rosenborg J, Larsson P, Lötvall J: Inhaled dry-powder formoterol and salmeterol in asthmatic patients: onset of action, duration of effect and potency. Eur Respir J 1997, 10:2489-2499.

4. Ringdal N, Derom E, Wahlin-Boll E, Pauwels R: Onset and duration of action of single doses of formoterol inhaled via Turbuhaler $^{\circledR}$. Respir Med 1998, 92:1017-1021.
5. Seberová $E$, Andersson A: Oxis ${ }^{\circledR}$ (formoterol given via Turbuhaler ${ }^{\circledR}$ ) showed as rapid an onset of action as salbutamol given by pMDI. Respir Med 2000, 94:607-6II.

6. Boonsawat W, Charoenratanakul S, Pothirat C, Sawanyawisuth K, Seearamroongruang T, Bengtsson T, Brander R, Selroos O: Formoterol (OXIS ${ }^{\circledR}$ ) Turbuhaler $^{\circledR}$ as a rescue therapy compared with salbutamol pMDI plus spacer in patients with acute severe asthma. Respir Med 2003, 97:1067-1074.

7. Rubinfeld A, Scicchitano R, Hunt A, Thompson PJ, Van Nooten A, Hedlund M, Hörstedt AS, Brander R: Formoterol turbuhaler is effective and safe compared with salbutamol by $\mathrm{pMDI}$ and spacer as reliever therapy in patients with acute severe asthma [Abstract No. P437]. Eur Respir J 2002, 20(Suppl 38): 4 Is.

8. Newnham DM, McDevitt DG, Lipworth BJ: Bronchodilator subsensitivity after chronic dosing with eformoterol in patients with asthma. Am J Med 1994, 97:29-37.

9. Grove A, Lipworth BJ: Bronchodilator subsensitivity to salbutamol after twice daily salmeterol in asthmatic patients. Lancet 1995, 346:201-206.

10. Aziz I, Lipworth BJ: A bolus of inhaled budesonide rapidly reverses airway subsensitivity and $\beta_{2}$-adrenoceptor downregulation after inhaled formoterol. Chest 1999, I | 5:623-628.

II. Pansegrouw DF: Acute resistant asthma caused by excessive beta-2-adrenoreceptor agonist inhalation and reversed by inhalation of beclomethasone. S Afr Med J 1992, 82:179-I82.

12. American Thoracic Society (ATS): Standards for the diagnosis and care of patients with chronic obstructive pulmonary disease (COPD) and asthma. Am Rev Respir Dis 1987, I36:225-244.

13. Quanjer PH, Tammeling GJ, Cotes JE, Pedersen OF, Peslin R, Yernault JC: Lung volumes and forced ventilatory flows. Report working party: standardization of lung function tests. European Community for Steel and Coal. Eur Respir J I993, 6(Suppl 16):5-40.

14. Pauwels RA, Sears MR, Campbell M, Villasante C, Huang S, Lindh A, Petermann W, Aubier M, Schwabe G, Bengtsson T, the RELIEF Study investigators: Formoterol as relief medication in asthma: a worldwide safety and effectiveness trial. Eur Respir J 2003, 22:787-794.

15. Tattersfield AE, Löfdahl CG, Postma DS, Eivindson A, Schreurs AGM, Rasidakis A, Ekström T: Comparison of formoterol and terbutaline for as-needed treatment of asthma: a randomised trial. Lancet 200I, 357:257-26I.

16. Balanag VM, Yunus F, Yang P-C, Jorup C: Budesonide/formoterol in a single inhaler is as effective and well tolerated as salbuta$\mathrm{mol}$ in relieving acute asthma in adults and adolescents [Abstract No. P2836]. Eur Respir J 2003, 22(Suppl 45):445s.

17. Rodrigo G, Rodrigo C: Inhaled flunisolide for acute severe asthma. Am J Respir Crit Care Med 1998, I 57:698-703.

18. Belleguic C, Corbel M, Germain N, Lena H, Boichot E, Delaval PH, Lagente V: Increased release of matrix metalloproteinase-9 in the plasma of acute severe asthmatic patients. Clin Exp Allergy 2002, 32:217-223.

19. Tillie-Leblond I, Gosset $P$, Tonnel AB: Inflammatory events in severe acute asthma. Allergy 2005, 60:23-29.

20. Engel T, Dirksen A, Heinig JH, Nielsen NH, Weeke S, Johansson A: Single-dose inhaled budesonide in subjects with chronic asthma. Allergy 1991, 46:547-553.

21. FitzGerald JM, Becker A, Sears MR, Mink S, Chung K, Lee J, for the Canadian Asthma Exacerbation Study Group: Doubling the dose of budesonide versus maintenance treatment in asthma exacerbations. Thorax 2004, 59:550-556.

22. Harrison TW, Oborne J, Newton S, Tattersfield AE: Doubling the dose of inhaled corticosteroid to prevent asthma exacerbations: randomised controlled trial. Lancet 2004, 363:27I-275.

23. Foresi A, Morelli MC, Catena E: Low-dose budesonide with the addition of an increased dose during exacerbations is effective in long-term asthma control. Chest 2000, I I 7:440-446.

24. O'Byrne PM, Bisgaard H, Godard PP, Pistolesi M, Palmqvist M, Zhu Y, Ekström T, Bateman ED: Budesonide/formoterol combination therapy as both maintenance and reliever medication in asthma. Am J Respir Crit Care Med 2005, I 7 I:129-136.

25. Scicchitano R, Aalbers R, Ukena D, Manjra A, Fouquert L, Centanni S, Boulet L-P, Naya IP, Hultquist C: Efficacy and safety of budesonide/formoterol single inhaler therapy versus a higher dose 
of budesonide in moderate to severe asthma. Curr Med Res Opin 2004, 20:1403-1418.

26. Ankerst J, Persson G, Weibull E: Tolerability of a high dose of budesonide/formoterol in a single inhaler in patients with asthma. Pulm Pharmacol Ther 2003, 16:147-15I.

27. Rosenborg J, Larsson P, Rott Z, Böcskei C, Poczi M, Juhasz G: Relative therapeutic index between inhaled formoterol and salbutamol in asthmatic patients. Respir Med 2002, 96:4I2-4I7.

Publish with Bio Med Central and every scientist can read your work free of charge

"BioMed Central will be the most significant development for disseminating the results of biomedical research in our lifetime. " Sir Paul Nurse, Cancer Research UK

Your research papers will be:

- available free of charge to the entire biomedical community

- peer reviewed and published immediately upon acceptance

- cited in PubMed and archived on PubMed Central

- yours - you keep the copyright

Submit your manuscript here:

http://www.biomedcentral.com/info/publishing_adv.asp 